\title{
CONSONANTAL ORGANIZATION IN ENGLISH POETIC DISCOURSE: TOPOLOGICAL PERSPECTIVE
}

\author{
Natalia Neborsina \\ Taras Shevchenko National University of Kyiv, Ukraine \\ nebnat2017@gmail.com
}

\begin{abstract}
The aesthetic reflection of the world in language finds its expression in the oldest, phonetic aspect of the word's meaning. Phonetic timbre is the distinctive quality in the sounds of words. A marked consistency of texture in poetic discourse is achieved by alliteration. There is a growing interest in its aesthetic measure. The aim of this article is to suggest, following G. Mazzola, a conceptual framework for consonantal analysis of poems in terms of the category of topological spaces. The topological space of the line is viewed as made of phonetic toposes. They include a consonant sound and its morphism. A consonant sound carries substance and is called "denotator". The conceptual form of denotator consists of Name, Type, and Coordinator. The name of the consonant represents the phonetic theme: the $n$ phonetic theme embraces high timbre consonants, while the $m$ phonetic theme includes low timbre consonants. Two types of consonance are singled out - complete consonance and incomplete consonance. The results of the analysis of poetic discourse show that complete consonance coordination has two forms: simple morphism and compound morphism. In case of incomplete consonance the morphism is intensified or lax. Phonetic topology may prove to be an effective mechanism in the study of "orchestration of voice" in poetic discourse as a socio-cultural phenomenon.
\end{abstract}

Keywords: alliteration; phonetic topology; G. Mazzola; simple morphism; compound morphism; intensified morphism; lax morphism.

\author{
I LOVE BAUDOUIN! \\ It turned out - \\ the cell is alive. \\ Out of it \\ one can grow \\ a squirrel, a rhinoceros, a dragonfly, a man. \\ Thus in a word \\ Baudouin found \\ animated being: \\ a phoneme.
}

Ramifies

through the thought.

Intensifies

round itself

the thinking field

And draws to itself and attracts.

Phoneme has opened itself to Baudouin,

to the first -

and only to him.

Mihail Panov, "Ode to Baudouin"

(N.Neborsina, Trans.)

\section{Introduction}

The aesthetic reflection of the world in language finds its expression in the oldest, phonetic aspect of the word's meaning. Phonetic timbre is the distinctive quality in the sounds of words. The memorable phonetic features of words, such as their liquidity, solidity, airness, pliability, tension, and softness stamp their imprint upon our auditory intelligence (Robson, 1959, pp. 29-30). In this connection the following question arises: Is there any way to promote the methodological conception for "phonetic intelligence" in poetic discourse?

Among different views on the issue of fundamental assumptions of humanitarian sciences one comes across the opinion concerning the necessary or possible invasion of mathematics. According to Mihajlov (2006), there exists a deep kinship between the stages of historical changes in mathematical axiomatics and the stages of the development of European culture and in future this kinship will become one of the most important scientific problems (pp. 480-481). 
As Yngve (2006) argues, new foundations for linguistics make it possible to reconstitute it as a natural science cognate with biology, chemistry, and physics. Two criteria (namely, predictions must agree with the results of observation; reproducibility of observational and experimental results) and four assumptions (namely, there is a real world out there to be studied; it is coherent; from valid premises we can conclude valid conclusions; observed effects stem from immediate real-world causes) have been developed by scientists over the past four centuries and have become quite stable and standard everywhere in the hard sciences (Yngve, 2006, p. 88).

All sciences, including literary studies, objectively may and objectively must be mathematically exact. Alluding to Aristotle, Udalov (2011) continues: "formalization", "mathematics" and "precision" have two opposite forms of exposing knowledge - quantitative (numerical) and qualitative (terminology) (pp. 23-31).

Within the last decade the digital humanities have experienced tremendous growth. The case in point is the use of digital tools is close reading of poetry (McCurdy, Lein, Coles \& Meyer, 2015). With the aim to visualize poetic sound, the initiators of this project admit a certain amount of skepticism on the part of those who adhere to traditional humanities and quote a prominent critic of the digital humanities, Stanley Fish, "You don't know what you're looking for and why you are looking for it, how then do you proceed?" (McCurdy, Lein, Coles \& Meyer, 2015, p. 2). Another new way of approaching alliteration is treating it as a mnemonic device with the aim to understand how it affects comprehension process (Lea, Rapp, Elfenbein, Mitchel \& Romine, 2008).

The aim of the article is to suggest a conceptual framework for the study of alliteration in terms of the category of topological spaces.

\section{Methods}

General topology is a basic discipline in mathematics. Humanities have already understood the deep impact of topological reasoning. Philological topology is founded on the binary opposition of invariant and variant, which conceptually correlate with the categories of continuity and discreteness. These categories form the cognitive basis for the formation of the categories of space and time. Since space is the extension of continuity, and time is the continuity of extension, they are uninterrupted.

According to G. Mazzola (2002), the cornerstone of topology is the concept of neighborhood. We are given a set Top of "points" of whatever nature and want to give an axiomatic account of what it means that we stay in a neighborhood of a selected point $x$. In topology, a neighborhood of $x$ is a set of points "surrounding" $x$ and containing "small deformations" points around $x$. Another requirement means that a neighborhood contains a "core" neighborhood around that point in the sense that this core neighborhood is also a neighborhood of all its elements. It follows then that in topology neighborhood is formed mostly by associations rather than by repetition of its members (Mazzola, 2002, p. 227).

The starting point of our research is the design of two phonetic themes (Berke, 1964). This is illustrated in Fig. 1.

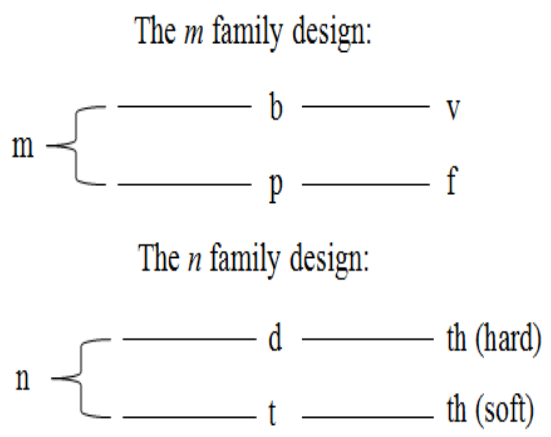

\section{Fig. 1. The schematic representation of the design of two phonetic themes}

The $m$ family can be enlarged by labial $w$ and the $n$ family - by alveolar $s, z, l$, post-alveolar $r$ and velar $k, g$.

In our research the notion of the family of consonants corresponds to the notion of neighborhood of consonantal sounds. The actual organization of consonants in phonetic lines is represented by local phonetic toposes, which include objects (invariants) and their morphisms (variants), i.e. reflections. These are sets of consonant sounds united by family resemblance.

According to Mazzola (2002), each point of a topological space carries its substance, or its form-space with it. The substance point is called a denotator. It has the pointer character. Denotator has a conceptual form which consists of Name, Type, and Coordinator. The name is any object. The type is a recursive start. It 
defines the object that begins ramification. The coordinator is a finite sequence $F_{t} \ldots, F_{n}$ of forms, it is the shape of the form (Mazzola, 2002, p. 50).

Let us now see how the denotator framework is projected on the local topological space of consonants (Fig. 2).

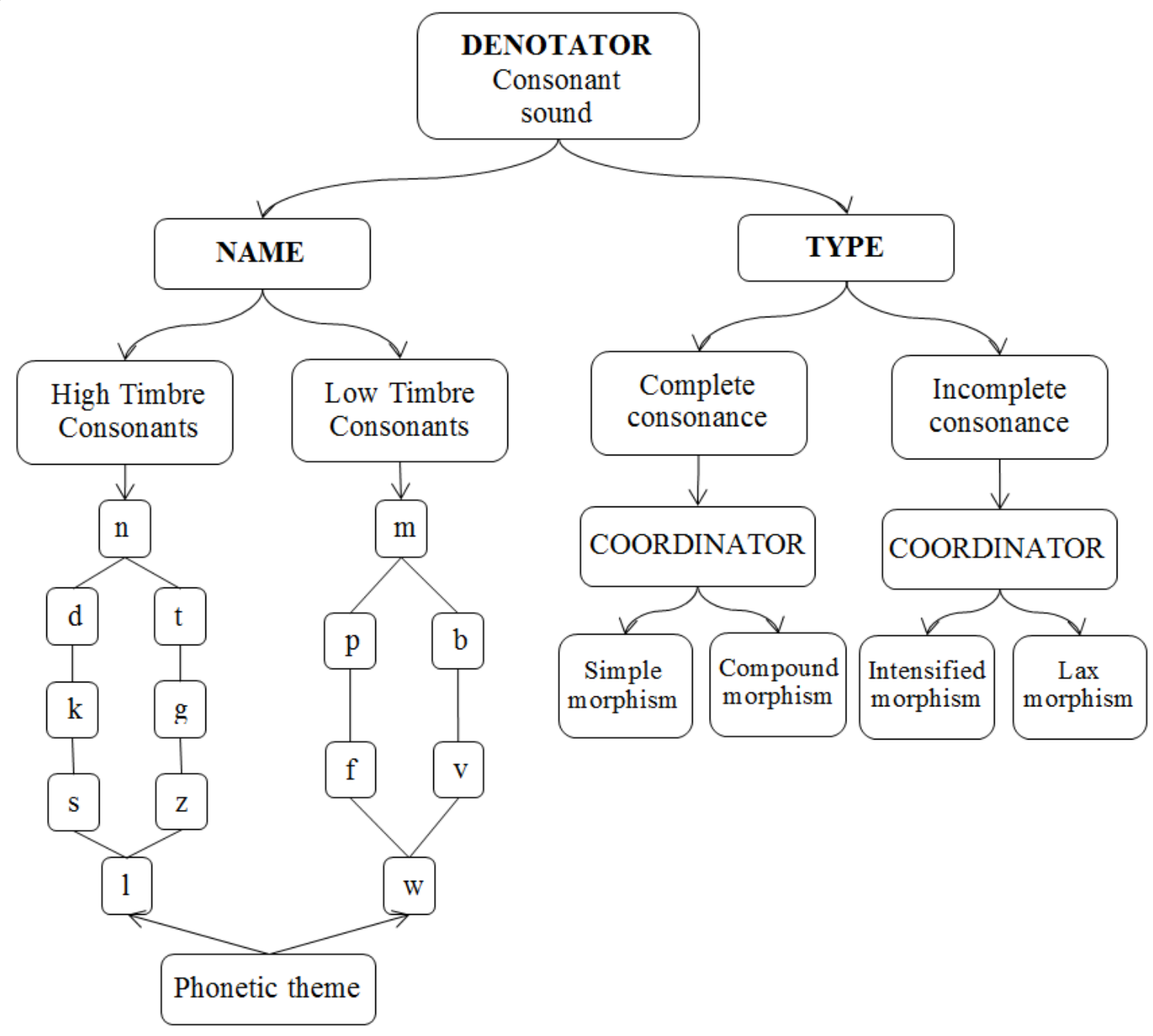

Fig. 2. Conceptual form of denotator applied to consonantal organization of poetic lines as local compositions

As Robson (1959) admits, poets write accordingly to their interest in the music of language (pp. 22-24). They also model implicitness of poetic discourse by psychologically motivated phonetic means (Ukrainets, 2015). To really understand the modification of consonant sounds in topological space and its relation to the aesthetic consequences, one has to take into consideration the neighborhood of different vowels.

\section{Results and Discussion}

The material which is presented below is organized in two sections according to the type of denotator. The objects of topological spaces are marked by dots above and below the consonant sound. The morphisms of the object are indicated by numerical sequence.

Phonetic toposes with complete consonance of the object and its morphism.

The Coordinator: Simple Morphism.

The phonetic theme is low timbre.

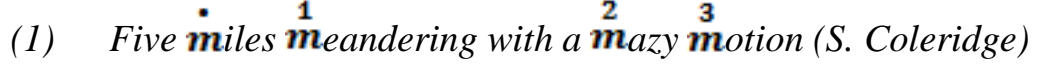

(2) All the breath and the bloom of the 
Year in the $\stackrel{2}{\mathbf{b}}$ ag of the $\stackrel{3}{\text { bee (R. Browning) }}$

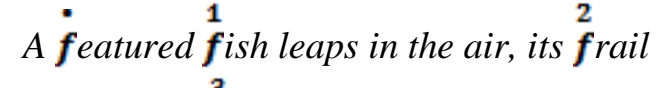

snow-white flesh encased in a monument (C. Crowther)

(4) They took the $\dot{\boldsymbol{w}}$ alls $\stackrel{1}{\mathbf{w}}$ ay $\stackrel{2}{\mathbf{w}}$ ithout $\stackrel{3}{\mathbf{w}}$ arning (C. Crowther)

(5) A bridge above the $\stackrel{2}{\mathbf{b}}$ right and $\stackrel{3}{\mathbf{b}}$ lue of water (W. Stevens)

The analysis shows that low timbre consonants $m, b, f, w$ are disposed to form topological spaces. The quantitative measure of simple morphism is three points irrespective of the stretch of discourse. The phonetic emotional plane of phonetic toposes depends on the environment of both, the denotator and its morphism. Thus in (1) the phonetic timbre of denotator $m$ and the first two morphisms occur in the high-vowel environment, while the third morphism is in the neighborhood of a low-toned vowel that synchronizes with the end of line pause.

In (2) the timbre of denotator $b$ and the first morphism are modified by the neighboring consonants $r$ and $l$, intensifying their explosiveness.

In (3) the denotator $f$ and its first morphism are both followed by high tone vowels; the second morphism is modified by mid low consonant $r$; the modification of the third morphism by high timbre consonant $l$ creates the effect of fadedness.

In (4) the topological space, created by the low timbre consonant $w$ reminds one of a path made of tight knots. However, if one overcomes the smooth flow of iambic pentameter by introducing caesura after the first morphism, the tone of natural conversation will transform the topological space and the aesthetic effect will be lost.

It is interesting to notice the partial similarity between (2) and (5). In both examples the denotator is the sound cluster $b r$ and the terminal morphism $b l$. Thus we can speak of two topological spaces sharing nearly the same phonetic emotional plane.
(6) The grinding water and the $\mathbf{g}$ asping wind (W. Stevens)
A $\dot{g}$ lobe, year world, by that impression $\stackrel{\mathbf{g}}{\mathbf{g}}$ row (J. Donne)
It $\dot{\boldsymbol{g}}$ lows and $\stackrel{\mathbf{1}}{\boldsymbol{g}}$ litters in my $\stackrel{\mathbf{2}}{\mathbf{c l}}$ loudy breast
like stars upon some $\stackrel{3}{\mathbf{g}}$ loomy $\stackrel{4}{\mathbf{g}}$ rove (H. Vaughan)
(9) Once I used to dread the dark, the hardness (S. Campbell)
- $12 \quad 3$
(10) But day doth daily draw my sorrows longer (W. Shakespeare)
(11) When to the $\dot{\boldsymbol{s}}$ ession of $\mathbf{1} \boldsymbol{s}_{\text {weet }} \mathbf{s}$ silent thought (W. Shakespeare)

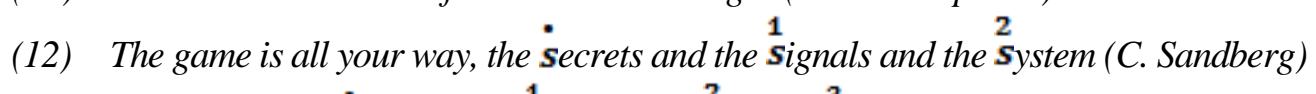
(13) I would rather sit still in a $\stackrel{\mathbf{1}}{\text { state of peace on a stone (D. Lawrence) }}$

The analysis proves that high timber consonants $g, d, s$ are more liable to begin the process of ramification. The range of quantitative measure of simple morphism is not stable, it varies from one to four points. The perception of the topological spaces varies. Thus, for example, in (6) and (7) the perception is decentralized and the effect is not sufficient, while in (10) it is centralized: the effect is given force by monosyllables (day, doth, draw).

\footnotetext{
The Coordinator: Compound Morphism

(14) The $\dot{\boldsymbol{m}}$ oon is the $\stackrel{\mathbf{m}}{\mathbf{m}}$ other of pathos and pity (W. Stevens)

(15) That was the summer of the early bees, of the ${ }_{1}$ ig heat,

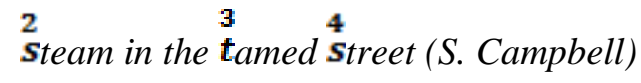


(16) $\dot{\text { Winds }} \stackrel{\stackrel{1}{w}}{\text { weather }} \stackrel{2}{\mathbf{w}}$ eather

3

Is $\boldsymbol{w}$ hat nasty people are

$\underset{1}{\text { Nasty about }} \mathbf{n}_{\mathbf{2}}$ d the $\underset{3}{\mathbf{n}}$ ice

Show a common joy in observing (H. Auden)

(17) The pain be mine, but thine shall be the ${ }_{\mathbf{1}}^{\mathbf{1}}$ raise (W. Shakespeare)

(18) If fell here like a feather would-

freely, no ${ }^{3}$ ear of the ground $-(J$. Bird $)$

Compound morphism is distinguished by a various consonantal organization of space. For example, in (14) the consonance is localized to one step of ramification of $\mathrm{m}_{\text {object }}$ and $\mathrm{p}$ object, both of them belong to one phonetic theme, but seem to produce the effect of contrast.

In (15) the object of morphism $S$ crosses over the object $b$. Although the morphism of the object $S$ is quantitatively bigger (four points) than the morphism of the object $b$, they both seem aesthetically effective, for they belong to different phonetic themes.

In (16) the phonetic themes are being interchanged: the objects of morphism $w \& n$ counterpoint, having both three steps of ramification.

In (17) the organization of consonantal topological space is chiastic: the object of morphism $p$ produces a distant step of ramification, while the object $n$ generates a close morphism. Together they produce the aesthetic effect of embracement.

The starting point of morphism in (18) is the object $f$ which produces three steps of ramification, making a strong horizontal path in the development of a topological space, which is crowned, as it were, by the vertical path of ramification of the object $d$ and its morphism. Although the horizontal topological space covered by the object $f$ is bigger, the vertical path which results in rhyme is no less effective having been accentuated by dashes.

Phonetic toposes with incomplete consonance of the object and its morphisms.

The Coordinator: Intensified Morphism.

(19) Why is my verse is barren of new pride (W. Shakespeare)

(20) Refined thee into blissful $\stackrel{1}{\text { paradise (J. Donne) }}$

(21) Spring's bright 1 paradise has come to this (W. Stevens)

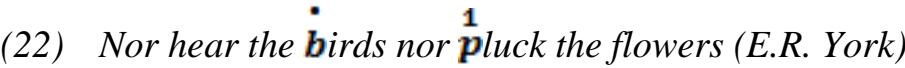

(23) And faithful Petrarch gloriously $\stackrel{1}{\text { crown'd (J. Keats) }}$

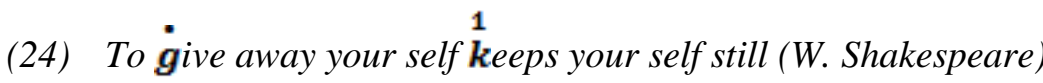

It should be admitted that the consonantal topological space coordinated by intensified morphism is marked by localized consonance with the object having a single modified morphism. The preference is given to low timber consonant sounds $b \rightarrow p$ : (19), (20), (21), (22). The less frequently used are high timber consonant sounds $g \rightarrow k$ as in (23), (24).

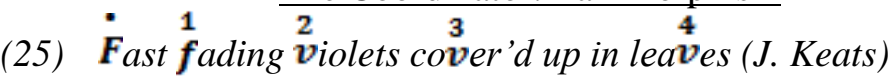

(26) A natural sermon o'ev their pebbly $\stackrel{1}{b} e d s$ (J. Keats)

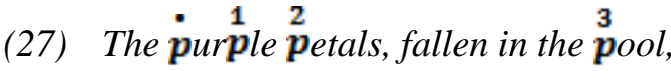
made the black water with their beauty gay (R.W. Emerson)

(28) O Father of eternal life, and all Created $\stackrel{1}{g}$ lories under thee! (H. Vaughan) 


\section{(29) The while they cool themselves, they freshly $\stackrel{\mathbf{1}}{\mathrm{g}}$ ive (J. Keats) \\ (30) My head cool-bedded in the flowery $\stackrel{1}{g}$ rass(J. Keats) \\ (31) When I consider everything that $\stackrel{1}{g}$ rows (W. Shakespeare)}

The use of Lax morphism in the progression of a consonantal topological space is characterized by the choice of low timbre consonants $f, p$ as objects and their modified lax morphisms $v, b$ as in (25), (26), (27), as well as high timber consonant $k$ as object and its modified lax morphism $g$ as in (28), (29), (30), (31). The example (27) is interesting in that it contains two topological spaces initiated by the contrastive objects of morphism $p$ and $b$. The example (29), (30) present some interest too by virtue of being similar not only in the choice of object and its morphism $(k \rightarrow g)$, but also in the distance of their consonance.

Conclusion. The current study provides an insight into the consonantal topological space in poetic discourse with the help of conceptual framework. It is claimed that the notion of consonantal topological space involves the phenomenon of alliteration as a significant device of artistic creation. The present results show that alliteration is more common and aesthetically effective in the cases of complete consonance of sounds coordinated by simple morphism. The organization of consonantal topological space becomes involved when it is coordinated by compound morphism. Incomplete consonance that results in two types of coordinator - lax morphism and intensified morphism, is characterized by the gradual lax of the aesthetic effect.

The study of consonantal topological organization opens up a new vista in understanding the poets' 'world', their interpretations of situations, actions and entities in poetic discourse and the importance of consonant sounds as its invigorator.

\section{References:}

Berke, K. (1964). On Musicality in Verse. In K. Berke, Perspectives by Incongruity (pp. 110-118). Bloomington, Indiana: Indiana University Press.

Broadbent, J. (Ed.). (1974). Poets of the 17th Century (Vol. 1). New York, US: A Signet Classics.

Eilson, J.D. (Ed.). (1969). The Works of Shakespeare. The Sonnets. Cambridge, UK: Cambridge University Press.

Gittings, R. (Ed.). (1966). Selected Poems and Letters of John Keats. London, UK: Heinemann.

Lea, R.B., Rapp, D.N., Elfenbein, A., Mitchel, A.D. \& Romine, R.S. (2008). Sweet silent thought: Alliteration and resonance in poetry comprehension. Psychological Science, 19, 7, 709-716. https://doi.org/10.1111/j.1467-9280.2008.02146.x

Lumsden, R. (Ed.). (2010).Identity Parade. New British \& Irish PoetsHexham. UK: Bloodaxe Books Ltd.

Mazzola, G. (2002). The Topos of Music. Geometric Logic of Concepts, Theory, and Performance. Zurich, Switzerland: Springer Basel AG. https:// doi.org/10.1007/978-3-0348-8141-8

McCurdy, N., Lein, J., Coles, K. \& Meyer, M. (2015). Poemage: Visualizing the Sonic Topology of a Poem. IEEE Transactions on Visualization and Computer Graphics. 22(1), 1-10. https://doi.org/10.1109/tvcg.2015.2467811

Mihajlov, A.V. (2006). O krizise $\mathrm{v}$ naukah i kulture [On the crisis in sciences and culture]. In A.V. Mihajlov, Izbrannoe. Istoricheskaja pojetika i germenevtika (pp. 471-520). St. Petersburg, Russia: Izdatelstvo SPbGU.

Robson, E.M. (1959). The orchestra of the language. New York, US: Thomas Yoseloff. https://doi.org/10.1063/1.3060895

Udalov, V.L. (2011). Problema tochnosti literaturovedenija i drugih nauk [The problem of literary precision in criticism and other sciences]. Visnyk Dnipropetrovskoho universytetu Ekonomiky ta Prava imeni Alfreda Nobelia. Seriia "Filolohichni nauky", 1 (1), 23-31.

Ukrainets, L.R. (2015). Estetyka psykholohichno motyvovanykh fonetychnykh odynyts (na mteriali ukrainskoi poetychnoi movy XX - XXI st.) [Aesthetics of psychologically motivated phonetic units (on the material of Ukrainian poetry of the $20^{\mathrm{th}}-21^{\mathrm{st}}$ centuries)]. Odeskyi linhvistychnyi visnyk, 6, 2, 122-124.

Yngve, V.N. (2006). An outline of Hard-Science Phonetics-Phonology. In V.N. Yngve, Z. Wasik, Hard-Science Linguistics. New York, US: Continuum.

Zemskaja, E.A. \& Kaljanchuk, M.L. (Eds.). (2007). Zhizn jazyka. Pamjati Mihaila Viktorovicha Panova [Life of language: To the memory of M.V. Panov].Moscow, Russia: Jazyki slavjanskoj kultury. 